\title{
SEROPREVALENCE OF HUMAN IMMUNODEFICIENCY VIRUS IN TUBERCULOSIS PATIENTS AT A TERTIARY CARE HOSPITAL IN WEST BENGAL: A RETROSPECTIVE STUDY
}

\author{
Tapan Das Bairagya ${ }^{1}$, Saurabh Biswas ${ }^{2}$ \\ ${ }^{1}$ Assistant Professor, Department of Chest Medicine, North Bengal Medical College, Darjeeling, West Bengal. \\ ${ }^{2}$ Assistant Professor, Department of Chest Medicine, North Bengal Medical College, Darjeeling, West Bengal.
}

\section{ABSTRACT}

\section{BACKGROUND}

Objectives of the study were to estimate the prevalence of HIV infection in pulmonary tuberculosis and extrapulmonary tuberculosis patients to study the presentation of tuberculosis in HIV seropositive patients and to study the risk factors for HIV among HIV infected patients.

\section{METHODS}

The study was carried out at the Pulmonary Medicine Department, R. G. Kar Medical College and Hospital, Kolkata. A total of 200 tuberculosis patients were studied. Criteria for case selection was clinico-bacteriological confirmed cases of pulmonary and extrapulmonary tuberculosis patients and they were selected for HIV serology testing according to NACO (National AIDS Control Organisation) guideline. Data were then analysed using Microsoft excel software.

\section{RESULTS}

Among 200 TB patients, 17 were found to be HIV seropositive (8.5\%). Among 21 tuberculosis patients who gave history of contact with CSW (Commercial sex worker), 12 (57.1\%) were found to be HIV seropositive. Fever, cough, significant weight loss and lymph node swelling were most common presentations of both TB and HIV. $12.9 \%$ patients of extrapulmonary tuberculosis patients were HIV seropositive in comparison to 5.7\% HIV seropositivity of pulmonary tuberculosis patients. Among 153 male tuberculosis patients 15 (9.8\%) and among 47 female tuberculosis patients two (4.25\%) were HIV seropositive. 32.5\% were in the age group of 20-49 yrs.

\section{CONCLUSION}

Extrapulmonary tuberculosis patient showed high seropositivity rate. Unprotected sexual exposure was the most common mode of transmission among tuberculosis patient.

\section{KEYWORDS}

Human Immunodeficiency Virus, Tuberculosis, Prevalence.

HOW TO CITE THIS ARTICLE: Bairagya TD, Biswas S. Seroprevalence of human immunodeficiency virus in tuberculosis patients at a tertiary care hospital in West Bengal: a retrospective study. J. Evolution Med. Dent. Sci. 2016;5(71):5148-5151, DOI: $10.14260 /$ jemds/2016/1167

\section{INTRODUCTION}

The Human Immunodeficiency Virus (HIV) infection and the Acquired Immune Deficiency Syndrome (AIDS) pandemic is one of the most devastating diseases that mankind has ever faced. Though the HIV pandemic began late in Asia, ${ }^{1}$ the situation is rapidly changing as South East Asia Region of the WHO accounts for nearly 40 percent of all tuberculosis cases globally and 18 percent of the world's HIV infected also live in this region. In developing countries, tuberculosis accounts for about a third of all AIDS death and the deadly synergy between HIV and TB. It is a leading cause of mortality in the developing country. ${ }^{2}$ The collision of the TB and HIV infection pandemic has resulted in $12-14$ million people become infected with both TB and HIV. Of the 15 countries with the highest rates of tuberculosis/human-immunodeficiency virus (TB/HIV) co-infection among adults, 12 are in Africa and the others in Asia including India, Myanmar and Thailand. ${ }^{3}$

Financial or Other, Competing Interest: None.

Submission 11-08-2016, Peer Review 23-08-2016,

Acceptance 26-08-2016, Published 02-09-2016.

Corresponding Author:

Dr. Tapan Das Bairagya,

F5, MO Qtrs., NBMC Campus,

Sushrutanagar, Darjeeling, West Bengal.

E-mail: tdasbairagya@gmail.com

DOI: $10.14260 /$ jemds/2016/1167
Infection with HIV results in progressive immunodeficiency and renders the infected person increasingly vulnerable to a wide range of pathogen. In many parts of the worlds including India, tuberculosis is the most common opportunistic infection in HIV infected person.

Individual who are not HIV infected and become infected with Mycobacterium tuberculosis have approximately 10\% lifetime risk of developing active tuberculosis compared to a risk of $60 \%$ or more in person infected with both HIV and TB. ${ }^{4}$ Stated otherwise, the risk of tuberculosis infection progressing to active tuberculosis is estimated to be $10 \%$ per year in a HIV positive person. This is particularly important in India where it is estimated that more than half of the population harbour Mycobacterium tuberculosis infection. 5

In both developed and developing countries, outbreaks of MDR-TB have spread rapidly in hospital wards for HIV infected patients. ${ }^{6}$

Many reports from India suggest a high seroprevalence of HIV among tuberculosis patients. Most reports are from western and southern states.

At the end of 2007, 33.2 million individuals were living with HIV infection (range: 30.6-36.1 million) according to the Joint United Nations Program on HIV/AIDS (UNAIDS). More than $95 \%$ of people living with HIV/AIDS reside in low- and middle-income countries; $\sim 50 \%$ are female, and 2.5 million are children $<15$ years. 
In 2007, there was an estimated 2.5 million new cases of HIV infection worldwide including 420,000 in children $<15$ years. In 2007, global AIDS deaths totalled 2.1 million (including 330,000 children $<15$ years). In 2013, an estimated 9 million people developed tuberculosis and 1.5 million died from disease, 36,000 of whom were HIV positive. In a tertiary hospital, HIV in TB patient also a challenge in our day-to-day practice. We have tried to present a picture of HIV seroprevalence in tuberculosis patients from our hospital.

The Human Immunodeficiency Virus has spread across India since the first cases of AIDS was registered in Chennai in 1986. According to the annual report published by NACO in 2002, there are an estimated 4.58 million HIV infected person in India. ${ }^{7}$ It was predicted that the HIV epidemic will lead to an additional 200,000 cases of TB per year in India. ${ }^{8}$

\section{MATERIAL AND METHOD}

The study was carried out at the Department of Pulmonary Medicine, R. G. Kar Medical College, Kolkata, during April 2007 to March 2008. A total 200 cases of tuberculosis were selected for HIV serology testing.

Sputum smear positive and sputum smear negative for acid-fast bacilli pulmonary tuberculosis patient were selected according to RNTCP (Revised National Tuberculosis Control Program) protocol and extrapulmonary tuberculosis patient were confirmed by following protocol:

1. Tuberculous pleural effusion by history, clinical examination, pleural fluid cytology, biochemistry, ADA (adenosine deaminase) level or biopsy feature suggestive of tuberculosis.

2. Lymph node tuberculosis by FNAC/histopathology/Mycobacterium tuberculosis culture.

3. CNS tuberculosis by history, clinical examination, CSF study (cell type, cell count, protein, sugar, ADA, tuberculosis culture, PCR).

4. Gastrointestinal and skeletal tuberculosis by history, clinical examination, radiological imaging and histopathology.

Pretest counseling of patients was done by ICTC (Integrated Counselling and Testing Centre) counsellor and their venous blood was sent to ICTC of R. G. Kar Medical College for HIV antibody (rapid/ELISA). Patients were classified according to their age, sex, marital status, high-risk behaviour and co-morbid condition. Detailed history was taken and clinical examination was done. Study reports were plotted in a proforma. Different variables were analysed according to our study design. Data were analysed using Microsoft excel software.

\section{RESULTS}

A total of 200 cases of tuberculosis patients were observed and 17 patients were found to be coinfected with HIV. Prevalence of coinfection varied with age of the patient. Table 1 shows that $6.8 \%$ of coinfected patients were in the $20-29$ year age group, $16.4 \%$ of coinfected patients were in the 30 39 years age group and $9.3 \%$ were in $40-49$ years age group. Among 153 male TB patients 15 (9.8\%) were seropositive for HIV and among 47 female TB patients two (4.25\%) were HIV seropositive. Table 2 shows that $12.9 \%$ patients of extrapulmonary tuberculosis patients were HIV seropositive in comparison to $5.7 \%$ of seropositivity among pulmonary tuberculosis patients. However, sample size of tuberculosis patient was too small to derive any conclusion, but majority of cases were due to unprotected sexual exposure (Table 3). Diarrhoea more than one month was most common presenting symptom in TB HIV coinfection, which was about $80 \%$. Swelling of the lymph gland was second most common symptom (21.87\%). Other symptoms were dyspnoea (15.38\%), weight loss (12.62\%), fever more than one month $(9.77 \%)$ and cough more than one month $(8.04 \%)$ in our study. Majority of coinfected patients had either lymph node tuberculosis or tuberculous pleural effusion. $10.9 \%$ coinfected male were sputum smear positive for AFB (Table 4). There was a definite rural and urban variation in my study. However, significance of this variation needs to be studied with a larger sample size.

Our study showed two (13.33\%) out of 15 tuberculosis patients with HIV coinfection were driver by occupation. Nine $(10 \%)$ out of 90 tuberculosis patients with HIV coinfection were manual worker by occupation and four (10.25\%) were businessman by occupation. (Table 5).

\begin{tabular}{|c|c|c|c|c|c|c|c|}
\hline \multirow[b]{3}{*}{$\begin{array}{l}\text { Age } \\
\text { Group }\end{array}$} & \multicolumn{6}{|c|}{ Number of Cases } & \multirow[b]{3}{*}{$\begin{array}{c}\text { Percentage } \\
\text { Prevalence of HIV } \\
\text { Among TB Patients }\end{array}$} \\
\hline & \multicolumn{3}{|c|}{ TB } & \multicolumn{3}{|c|}{ HIV } & \\
\hline & $\frac{\circlearrowright}{\sum^{\pi}}$ & 㓂 & 䒿 & $\frac{0}{\frac{0}{n}}$ & 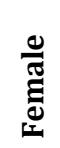 & $\stackrel{\pi}{\stackrel{\pi}{0}}$ & \\
\hline $12-19$ & 6 & 6 & 12 & 0 & 0 & 0 & $0 \%$ \\
\hline $20-29$ & 28 & 16 & 44 & 2 & 1 & 3 & $6.8 \%$ \\
\hline $30-39$ & 47 & 14 & 61 & 9 & 1 & 10 & $16.4 \%$ \\
\hline $40-49$ & 36 & 7 & 43 & 4 & 0 & 4 & $9.3 \%$ \\
\hline $\begin{array}{l}50 \text { and } \\
\text { Above }\end{array}$ & 36 & 4 & 40 & 0 & 0 & 0 & $0 \%$ \\
\hline Total & 153 & 47 & 200 & 15 & 2 & 17 & $8.5 \%$ \\
\hline
\end{tabular}

\begin{tabular}{|c|c|c|c|}
\hline Category & TB & HIV & $\begin{array}{c}\text { Percentage Prevalence } \\
\text { of HIV Among TB }\end{array}$ \\
\hline Pulmonary & 123 & 7 & $5.7 \%$ \\
\hline Extrapulmonary & 77 & 10 & $12.9 \%$ \\
\hline Total & $\mathbf{2 0 0}$ & $\mathbf{1 7}$ & $\mathbf{8 . 5 \%}$ \\
\hline \multicolumn{4}{|c|}{ Table 2: HIV in TB Cases According to } \\
Pulmonary and ExtrapuImonary Category
\end{tabular}

HIV in TB cases according to Pulmonary and extra-pulmonry Category

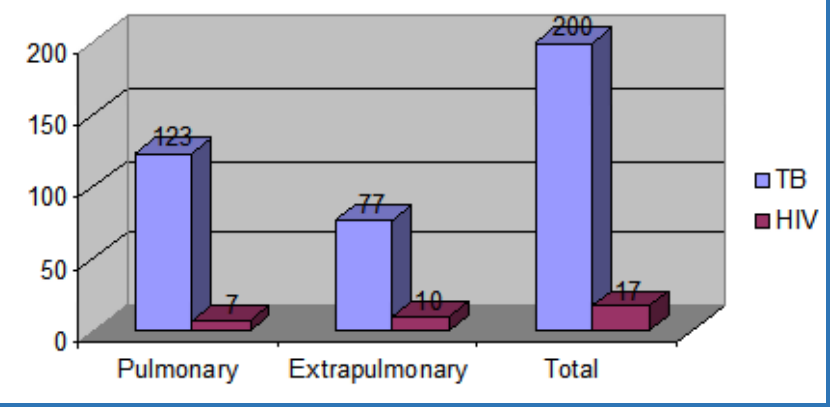




\begin{tabular}{|c|c|c|c|}
\hline \multirow{2}{*}{ Category } & \multicolumn{2}{|c|}{ No. of Cases } & \multirow{2}{*}{$\begin{array}{l}\text { Percentage } \\
\text { Prevalence }\end{array}$} \\
\hline & TB & HIV & \\
\hline $\begin{array}{c}\text { Contact with CSW } \\
\text { (Unprotected Sexual } \\
\text { Exposure) }\end{array}$ & 21 & 12 & $57.1 \%$ \\
\hline History of Blood Transfusion & 18 & 2 & $11.1 \%$ \\
\hline IV Drugs User & 1 & 1 & $100 \%$ \\
\hline STD & 7 & 1 & $14.2 \%$ \\
\hline $\begin{array}{c}\text { No History of High-Risk } \\
\text { Behaviour }\end{array}$ & 153 & 1 & $0.6 \%$ \\
\hline Total & 200 & 17 & $8.5 \%$ \\
\hline
\end{tabular}

\begin{tabular}{|c|c|c|c|c|c|c|}
\hline \multirow{2}{*}{ Category } & \multicolumn{2}{|c|}{ Male } & Percentage & \multicolumn{2}{|l|}{ Female } & Percentage \\
\cline { 2 - 6 } & Prevalence & TB & HIV & Prevalence \\
\hline $\begin{array}{c}\text { Sputum Smear } \\
\text { Positive PTB }\end{array}$ & 64 & 7 & $10.9 \%$ & 14 & 0 & 0 \\
\hline $\begin{array}{c}\text { Sputum Smear } \\
\text { Negative PTB }\end{array}$ & 31 & 0 & 0 & 14 & 0 & 0 \\
\hline Lymph Node TB & 16 & 2 & $12.5 \%$ & 12 & 2 & $16.7 \%$ \\
\hline Pleural Effusion & 42 & 6 & $14.3 \%$ & 7 & 0 & 0 \\
\hline Other EPTB & Nil & Nil & & Nil & Nil & 0 \\
\hline Total & 153 & 15 & $9.8 \%$ & $\mathbf{4 7}$ & $\mathbf{2}$ & $\mathbf{4 . 3 \%}$ \\
\hline
\end{tabular}

\begin{tabular}{|c|c|c|c|}
\hline Category & TB & HIV & \% Prevalence \\
\hline Businessman & 39 & 4 & $10.25 \%$ \\
\hline Manual Worker & 90 & 9 & $10 \%$ \\
\hline Driver/Transport Worker & 15 & 2 & $13.33 \%$ \\
\hline Govt. Serviceman & 5 & 0 & 0 \\
\hline Housewife & 39 & 2 & $5.1 \%$ \\
\hline Commercial Sexual Worker & 0 & 0 & 0 \\
\hline Student & 12 & 0 & 0 \\
\hline Total & 200 & 17 & $\mathbf{8 . 5 \%}$ \\
\hline Table 5: HIV Seroprevalence of Tuberculosis \\
Patients According to Their Occupation \\
\hline
\end{tabular}

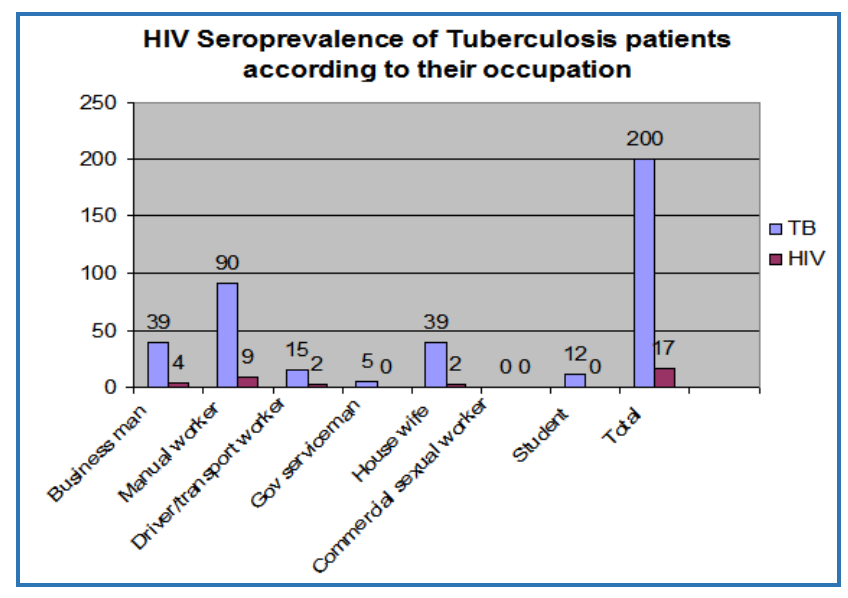

\begin{tabular}{|c|c|c|c|}
\hline Residence & TB & HIV & $\begin{array}{c}\text { Percentage } \\
\text { Prevalence }\end{array}$ \\
\hline Urban & 124 & 13 & $10.4 \%$ \\
\hline Rural & 76 & 4 & $5.2 \%$ \\
\hline Total & $\mathbf{2 0 0}$ & $\mathbf{1 7}$ & $\mathbf{8 . 5 \%}$ \\
\hline \multicolumn{4}{|c|}{$\begin{array}{c}\text { Table 6: HIV Seroprevalence } \\
\text { According to Residential Status }\end{array}$} \\
\hline
\end{tabular}

\section{DISCUSSION}

The published report about seroprevalence of HIV among tuberculosis patients give highly variable rate worldwide. The rates of HIV/TB coinfection have been reported to vary in different regions of India. It was found to be between $0.4 \%$ and $20.1 \%$ in north India. ${ }^{9}$ However, the incidence was $3.2 \%$ in 1991 , which increased to $20.1 \%$ in south India. ${ }^{10}$ In present study, $8.5 \%$ were found seropositive.

Most of our patients who had HIV along with Tuberculosis belonged to age group of $20-49$ years $(32.5 \%)$ represent sexually active and productive age group. This could be attributed to the fact that this population were mostly working or staying alone away from their home. Among them, 15 (9.8\%) male and two (4.2\%) female had HIV along with TB. Similar result have been reported by other studies in India, Jain S. K. et al 2000, Kumar P. et al 2002, Swaminathan S. et al 2002.11,12

The occupational profile of our patients revealed that majority of TB-HIV coinfected patients were driver/transport worker (13.33\%) followed by businessman (10.25\%) and manual labour $(10 \%)$. Kumar P. et al,11 Purohit et al ${ }^{13}$ reported similar occupational profile among HIV in TB patients.

Fever, cough with expectoration, significant weight loss and anorexia were the common symptoms. Kumar P et al,11 Swaminathan $\mathrm{S}$ et $\mathrm{al}^{12}$ and Deivanayagam et al reported cough with expectoration to be the most common complaints followed by fever and weight loss. Purohit et al ${ }^{13}$ and Mohanty et al 14 found fever to be the most common complaints. In our study, Diarrhoea more than one month and glandular swelling and haemoptysis were common presenting complaints.

There was definite rural-urban variation in my study$10.4 \%$ coinfected patients were Urban and $5.2 \%$ were residing in rural area.

\section{CONCLUSION}

The close link between TB and HIV also requires enhanced collaboration and harmonisation of efforts in order to prevent HIV and to manage TB within the framework of the comprehensive care continuum from institution to community and home. NACO-RNTCP work together against this deadly duo to maximise their outputs from the limited resources available. Enhanced political commitment, integrating relevant activities in various programmes and strengthening partnerships with governmental and nongovernmental sectors will help to meet the challenge posed by the dual epidemic. An attempt is made in this study to provide an overview of the problem as it relates to Asia and the Pacific region.

\section{REFERENCES}

1. Joint United Nations programme on HIV/AIDS (UNAIDS) and World Health Organization (WHO) 2002. AIDS epidemic update December 2002. UNAIDS/02-58E Geneva: UNAIDS 2002.

2. Narain JP, Tripathy S, Pontali E. Tuberculosis and HIV infection. In: Narain JP, ed. Tuberculosis: Epidemiology and control. New Delhi: World Health Organization Regional office for South East Asia 2002. 
3. Havlir DV, Barnes PF. Tuberculosis in patients with human immunodeficiency virus infection. N Engl J Med 1999;340(5):367-73.

4. Telzak EE. Tuberculosis and human immunodeficiency virus infection. Med Clin North Am 1997;81(2):345-60.

5. World Health Organization. Research for action. Understanding and controlling tuberculosis in India 2000.

6. Centers for disease control. Nosocomial transmission of multidrug-resistant tuberculosis among HIV-infected persons--Florida and New York, 1988-1991. MMWR Morb Mortal Wkly Rep 1991;40(34):585-91.

7. Central TB Division, DGHS, Ministry of health and family welfare, New Delhi. TB India: RNTCP status report 2004.

8. Khatri GR, Frieden TR. Controlling tuberculosis in India. N Engl J Med 2002;347(18):1420-5.

9. Sharma SK, Aggarwal G, Seth P, et al. Increasing HIV seropositivity among adult tuberculosis patients in Delhi. Indian J Med Res. 2003;117:239-42.
10. Paranjape RS, Tripathy SP, Menon PA, et al. Increasing trend of HIV seroprevalence among pulmonary tuberculosis patients in Pune, India. Indian J Med Res. 1997; 106:207-11.

11. Kumar P, Sharma N, Sharma NC, et al. Clinical profile of tuberculosis in patients with HIV infection/AIDS. Indian J Chest Dis Allied Sci 2002;44(3):159-63.

12. Swaminathan S, Sangeetha M, Arunkumar N, et al. Pulmonary tuberculosis in HIV positive individuals: Preliminary report on clinical features and response to treatment. Indian J Tuberc 2002;49:189-93.

13. Purohit SD, Gupta RC, Bhatura VK. Pulmonary tuberculosis and human immunodeficiency virus infection in Ajmer. Lung India 1996;14(3):113-20.

14. Mohanty KC, Basheer PMM. Changing trend of HIV infection and tuberculosis in Bombay area since 1988. Indian J Tuberc 1995;42:117-20. 